\title{
PREPARAÇÃo E CARACTERIZAÇÃo DO VINHO DE LARANJA
}

\author{
Marcos L. Corazza, Dina G. Rodrigues e Jorge Nozaki* \\ Departamento de Química, Universidade Estadual de Maringá, Av. Colombo, 5790, 87020-900 Maringá - PR
}

Recebido em 26/1/00; aceito em 27/11/00

\begin{abstract}
PREPARATION AND CHARACTERIZATION OF ORANGE WINE. A simple method of home made preparation and physical-chemical characterization of orange wine was investigated. Saccharomyces cerevisiae was used as inoculum for wine-making by fermentation. Chemical compositions related to the aroma components seems to be very similar between grape and orange wines.
\end{abstract}

Keywords: fermentation; orange wine; chemical characterization.

\section{INTRODUÇÃo}

A citricultura é a mais recente alternativa agrícola da região noroeste do Estado do Paraná, e o município de Paranavaí é o maior produtor de laranjas da região. A produção atual é de 125 mil toneladas anuais, com expectativas de produção de 210 mil toneladas em 2001. A Paraná Citrus e a CITROCOP são as responsáveis pela transformação da laranja e a exportação do suco e seus subprodutos como o óleo essencial e o d-limoneno ${ }^{1}$.

Os óleos essenciais são óleos voláteis que são retirados das cascas das frutas cítricas e, tem aplicações variadas nas indústrias farmacêuticas e alimentíceas. O d-limoneno é uma fração oleosa, sendo considerada uma das mais puras fontes de terpeno monocíclico. Outro subproduto importante da laranja é o farelo de polpa cítrica ou farelo de casca de laranja. Este farelo é obtido por meio do tratamento de resíduos sólidos e líquidos remanescentes da extração do suco. O farelo da polpa cítrica peletizado é utilizado como complemento de ração animal na pecuária, tendo boa aceitação como insumo na ração de bovinos ${ }^{2}$.

O cultivo da laranja em escala comercial, no Estado do Paraná, está restrito aos terrenos arenosos da região de Paranavaí e, quanto ao reaproveitamento dos subprodutos da laranja, são necessários estudos para que esta atividade seja economicamente rentável para a região. Por outro lado, a citricultura e especialmente os seus subprodutos, constituemse em uma das mais importantes atividades econômicas no Estado de S. Paulo, a maior produtora do país, conforme os dados da Tabela 1.

\section{OBTENÇÃO DO VINHO}

O vinho é uma bebida alcoólica fermentada por difusão, que é obtido genericamente pela fermentação alcoólica de um suco de fruta natural madura, principalmente a uva (Vitis vinífera). Admitem-se, tradicionalmente, que o nome vinho seja reservado só para a bebida proveniente da uva. Para bebidas produzidas por fermentação alcoólica que não seja a uva, devese indicar o nome da fruta, como no caso atual, o vinho de laranja. Qualquer fruta que contenha níveis razoáveis de açúcar é possível de se produzir um bom vinho, com sabores característicos de cada fruta. Segundo a Legislação Brasileira, os vinhos são divididos quanto à classe em: vinho de mesa, com um teor alcoólico de 10 e $13^{\circ} \mathrm{GL}$ (graus Gay-Lussac); vinho champanha, contendo de 10 a $13^{\circ} \mathrm{GL}$; espumante, entre 7 e $10^{\circ} \mathrm{GL}$; espumante gaseificado entre 10 e $12,5^{\circ} \mathrm{GL}$; e licoroso, entre 14 e $18^{\circ} \mathrm{GL}$, podendo ser tintos, rosados, ou brancos em cada caso. A Legislação estabelece ainda que para os vinhos de frutas a graduação alcoólica esteja entre 10 e $14^{\circ} \mathrm{GL}$ e, a adição de sacarose poderá ser, no máximo, igual à dos açúcares da fruta ${ }^{3}$. Existem ainda o vinho de fruta gaseificado, em que se adicionou anidrido carbônico e o vinho de fruta licoroso, cuja graduação alcoólica vai de 13 a $18^{\circ} \mathrm{GL}$, este último pode ser doce ou seco $^{3}$.

Em geral, as operações envolvidas no processo de fabricação de vinhos são: extração e preparo do mosto; fermentação alcoólica; trasfega; clarificação e conservação. A nível industrial, portanto o mais difundido, estas operações são aplicadas na produção do vinho de uva. Por outro lado, o vinho de laranja não é uma bebida com grande comercialização no Brasil, apesar de ser conhecida há anos a possibilidade de sua fabricação.

\section{FERMENTAÇÃO ALCOÓLICA}

A fermentação alcoólica, a mais importante na fabricação do vinho, abrange toda a etapa desde o preparo do inóculo até a etapa de trasfega. No processo de fermentação pode-se distinguir três fases: uma preliminar que é de adaptação da cultura ao

Tabela 1. Subprodutos da laranja e produção de 1998/1999 no Estado de S. Paulo

Rendimentos da laranja em subprodutos em (\%)

Sucos células congeladas óleos essenciais $\quad$ D-limoneno líquidos aromáticos farelo de polpa cítrica

\begin{tabular}{|c|c|c|c|c|c|}
\hline 44,81 & 2,67 & $\begin{array}{c}1,79 \\
19.625^{*}\end{array}$ & $\begin{array}{c}0,92 \\
20.343^{*}\end{array}$ & 0,57 & $\begin{array}{c}49,24 \\
899365 *\end{array}$ \\
\hline
\end{tabular}

*Produção da safra de 1998/1999 (em toneladas)

Fonte: Instituto de Economia Agrícola e Coordenadoria de Assistência Técnica Integral, 2000 
meio, outra tumultuosa e, a fase complementar que é o fim da fermentação. A fermentação compreende um conjunto de reações enzimaticamente controladas, através das quais uma molécula orgânica é degradada em compostos mais simples liberando energia. O processo tem início com a ativação da glicose, que recebe em reações sucessivas dois fosfatos energéticos, fornecidos por duas moléculas de ATP (adenosina trifosfato) que se transforma em ADP (adenosina difosfato). A glicose, por sua vez, se transforma em gliceraldeido 1,3-difosfato. Ao final, cada gliceraldeído é transformada em ácido pirúvico. O rendimento é de duas moléculas de ATP para cada molécula de glicose utilizada ${ }^{4}$.

No geral, a principal reação seria:

$$
\mathrm{C}_{6} \mathrm{H}_{12} \mathrm{O}_{6} \rightarrow 2 \mathrm{CH}_{3} \mathrm{CH}_{2} \mathrm{OH}+\mathrm{CO}_{2}+33 \text { cal. }
$$

Durante o processo fermentativo com o $S$. cerevisiae as principais variáveis devem ser bem controladas, caso contrário, podem ocorrer variações na composição química do suco pela presença do Gluconobacter oxydans ${ }^{5}$, variação no conteúdo de ácido ascórbico ${ }^{6}$, fermentação do citrato, juntamente com a glicose, na presença do L. plantarum com a produção de ácido acético e do vinagre ${ }^{7,8,9}$, etc.

A fabricação caseira do vinho de laranja, utilizando-se frutos que não encontram demanda comercial devido a defeitos nas cascas e tamanhos, foram investigados como alternativa de consumo das mesmas.

\section{MATERIAIS E MÉTODOS}

A produção caseira do vinho de laranja consistiu nas etapas abaixo, utilizando-se um fermentador caseiro conforme a Figura 1.

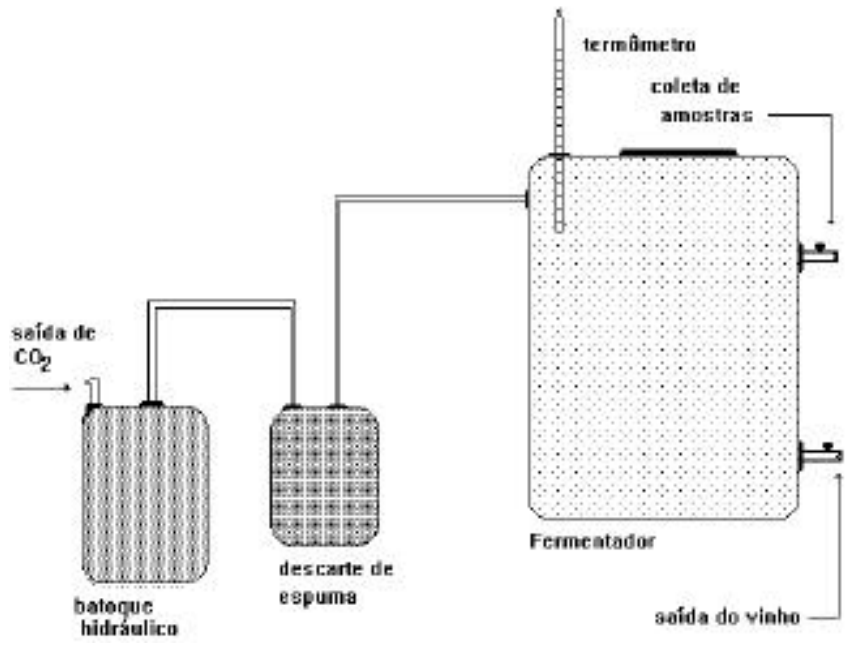

Figura 1. Fermentador caseiro utilizado na produção de vinho de laranja.

\section{Obtenção e classificação dos frutos}

As frutas, da região de Paranavaí-PR., foram classificadas de acordo com o estado de amadurecimento (maturação). Foram escolhidas as frutas sadias, descartando-se as demais.

\section{Extração do mosto}

Consistiu em separar o suco do restante da laranja utilizando-se um espremedor de frutas elétrico e, em seguida coado, em um coador manual.

\section{Preparo do mosto (sulfitagem)}

Utilizou-se o metabissulfito de sódio a $10 \%(\mathrm{~m} / \mathrm{v})$. Após a aplicação, deixou-se em repouso durante 3 horas, coado, sendo que o mosto fora previamente fervido e resfriado à temperatura ambiente.

\section{Determinação do grau Brix e correção do açúcar}

O grau Brix indica o teor aproximado de açúcar no mosto. Assim, um mosto com $10^{\circ}$ Brix contém aproximadamente $10 \%$ de açúcar. Considerando-se que 2 graus Brix produz aproximadamente $1^{\circ} \mathrm{GL}$ após a fermentação, a correção foi feita adicionando-se açúcar (sacarose) ao mosto, para a produção alcoólica desejada. As leituras do grau Brix foram feitas em refratômetro (Carl Zeiss), onde cada grau Brix representa aproximadamente $15 \mathrm{~g}$ de açúcar dissolvido para cada litro de mosto. O aparelho foi calibrado em banho termostatizado a $20^{\circ} \mathrm{C}$ com água deionizada $\left({ }^{\circ}\right.$ Brix $\left.=0\right)$ e, a seguir, foram feitas as leituras das amostras a $20^{\circ} \mathrm{C}$.

\section{Correção de acidez}

A determinação da acidez total foi feita por titulação volumétrica com solução de $\mathrm{NaOH} 0,1 \mathrm{~mol} \mathrm{~L}^{-1}$, e a solução alcoólica de fenolftaleína a $1 \%$ como indicador. Foram utilizados em cada titulação $10 \mathrm{~mL}$ do mosto, diluído a $50 \mathrm{~mL}$ com água destilada e 3 gotas de fenolftaleína. As correções de acidez foram feitas com soluções de $\mathrm{CaCO}_{3}$.

\section{Preparo do inóculo}

Utilizou-se o Saccharomyces cerevisiae na quantidade adequada $^{3,10}$.

\section{Densidade do mosto}

Determinou-se a densidade do mosto pesando-se inicialmente um balão volumétrico de $25 \mathrm{~mL}$ limpo e seco. Pesou-se novamente o balão contendo água destilada até o menisco. A seguir, lavou-se cuidadosamente com álcool etílico e éter etílico e pesou-se o balão com a amostra do mosto. A densidade do mosto foi calculada pela fórmula $D=\left(w-b_{2}\right) /\left(h-b_{1}\right)$.

Onde $\mathrm{w}=$ massa da amostra; $\mathrm{h}=$ massa da água; $\mathrm{b}_{2}=$ massa do balão na segunda pesagem e $b_{1}$ a massa do balão na primeira pesagem.

\section{Sólidos suspensos}

Os sólidos suspensos foram determinados pelas medidas no turbidímetro, em cubetas de vidro (Turbidímetro Micronal B 250).

\section{Grau alcoólico $\left({ }^{\circ} \mathrm{GL}\right)$}

Foram transferidos $200 \mathrm{~mL}$ da amostra, à temperatura ambiente, a um balão de destilação contendo $10 \mathrm{~mL}$ de água, e a uma coluna de destilação e esta a um condensador. Foram recolhidos 3/4 do volume inicial pela destilação, completou-se o volume com água destilada na mesma temperatura inicial. Determinou-se a densidade da amostra pelo mesmo procedimento anterior. Para o cálculo do grau alcoólico, utilizou-se uma tabela de densidade $\mathrm{x}$ grau alcoólico ${ }^{3}$.

\section{Trasfega}

Foi a transferência, após a filtração, do fermentado já pronto do reator para outro recipiente.

\section{Clarificação}

A clarificação do vinho pode ser feita com a bentonita, gelatina, albumina, etc. Utilizou-se neste trabalho a clara de ovo (albumina), na proporção de uma colher de sopa por litro do vinho. 


\section{Conservação}

Após a filtração e aquecimento em banho-maria a $65^{\circ} \mathrm{C}$ por 20 minutos, o vinho foi resfriado naturalmente e a conservação foi feita engarrafando-se o vinho em frascos de vidro e fechados com rolhas adequadas.

\section{RESULTADOS E DISCUSSÂO}

Na Tabela 2 aparecem os dados experimentais do processo de fermentação de 4,5 litros de sucos, correspondentes a $8 \mathrm{~kg}$ de laranjas pêras. O Brix foi corrigido a cada 12 h, no início para 15 e depois para $26^{\circ}$ Brix. Após $24 \mathrm{~h}$ de inoculação, adicionou-se ao mosto já preparado e previamente fervido. As variações de $\mathrm{pH}$, acidez total e densidade ocorridas durante a fermentação aparecem na Tabela 3. Observou-se os decréscimos no grau Brix e a densidade durante a fermentação. A acidez total elevou-se bruscamente somente no início, permanecendo praticamente constante durante a fermentação, portanto, foi suficiente a adição de pequenas quantidades de $\mathrm{CaCO}_{3}$ durante a preparação do mosto.

Conforme se observa na Figura 2, a variação do grau Brix com o tempo de fermentação, existem duas fases distintas. Nas primeiras 28-30 horas a fermentação é tumultuosa, com rápido consumo do açúcar do mosto, ou seja, alta atividade dos microorganismos. Numa segunda fase, menos tumultuosa, observa-se menor atividade das leveduras. Estas variações descendentes do grau Brix coincidem com a diminuição da intensidade de borbulhamento do dióxido de carbono no batoque hidráulico do fermentador (Figura 1). Observa-se ainda que, no final da fermentação, o grau Brix permaneceu em aproximadamente 8, de forma constante. Este fato deve-se, provavelmente, à presença de açúcares não fermentecíveis no suco de laranja.

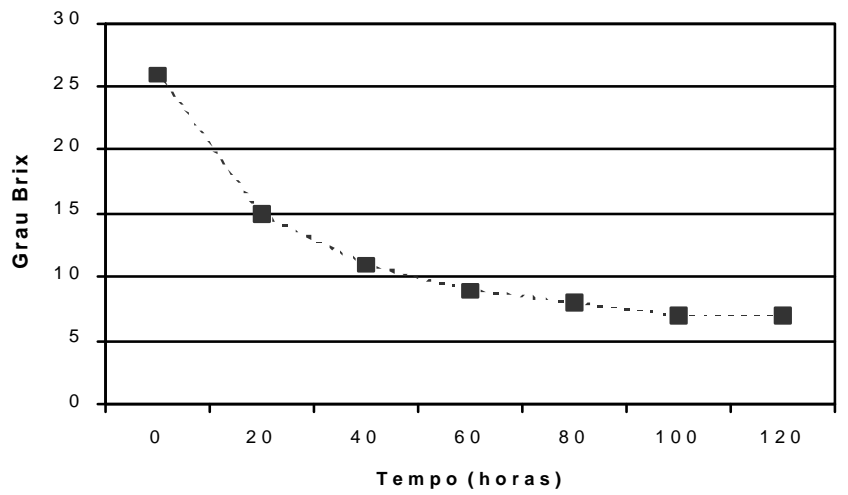

Figura 2. Variação do grau Brix x tempo.

De acordo com a Tabela 3, a densidade do mosto decresceu durante a fermentação, de acordo com o consumo de açúcar e a produção de etanol no processo fermentativo. A elevação da acidez total foi também muito rápida nas primeiras 24 horas de fermentação, permanecendo então constante, após este período, até o final da fermentação, conforme se observa na Figura 3.

Um dos principais fatores da qualidade de um vinho é a sua composição fenólica. As substâncias fenólicas são reativas em presença de oxigênio, pela transformação de fenóis em quinonas e a polimerização de flavanóides, alterando assim a turbidez, sabor e aroma do vinho ${ }^{11}$. A remoção dos compostos fenólicos foi uma tentativa para a melhora das qualidades sensoriais de certos tipos de vinhos ${ }^{12}$. As tentativas mais bem sucedidas foram com a utilização de produtos enológicos como a gelatina, caseína, albumina, carvão ativado e certos polímeros como a polivinilpolipirrolidona $(\mathrm{PVPP})^{12}$. No caso da produção do

Tabela 2. Processo de fermentação para a obtenção dovinho de laranja.

\begin{tabular}{|c|c|c|c|c|}
\hline Dados do suco & $\begin{array}{l}{ }^{o} \mathrm{Brix} \\
9,5\end{array}$ & $\begin{array}{c}\mathrm{pH} \\
3,64\end{array}$ & $\begin{array}{l}\text { acidez total }\left(\mathrm{g} \mathrm{L}^{-1}\right) \\
5,96\end{array}$ & $\begin{array}{c}\text { densidade }\left(\mathrm{g} \mathrm{cm}^{-3}\right) \\
1,0995\end{array}$ \\
\hline $\begin{array}{l}\text { Formulação } \\
\text { do mosto }\end{array}$ & $\begin{array}{c}\text { açúcar } \\
\text { adicionado }\left(\mathrm{g} \mathrm{L}^{-1}\right) \\
247,5\end{array}$ & $\begin{array}{c}\mathrm{CaCO}_{3} \\
\text { adicionado }\left(\mathrm{g} \mathrm{L}^{-1}\right) \\
1,47\end{array}$ & $\begin{array}{c}\text { água } \\
\text { adicionada }(\mathrm{L}) \\
0,7\end{array}$ & $\begin{array}{c}\text { volume } \\
\text { do suco }(\mathrm{L}) \\
2,7\end{array}$ \\
\hline $\begin{array}{l}\text { Formulação } \\
\text { do inóculo }\end{array}$ & $\begin{array}{l}\text { volume do } \\
\text { mosto (mL) } \\
150\end{array}$ & $\begin{array}{l}\text { quantidade de } \\
\text { de fermento }\left(\mathrm{g} \mathrm{L}^{-1}\right) \\
10\end{array}$ & $\begin{array}{c}{ }^{\circ} \text { Brix } \\
26\end{array}$ & $\begin{array}{l}\mathrm{pH} \\
3,0\end{array}$ \\
\hline
\end{tabular}

Tabela 3. Variações do $\mathrm{pH}$, densidade do mosto e acidez total durante a fermentação

\begin{tabular}{cccccc}
\hline $\begin{array}{c}\text { Tempo de } \\
\text { fermentação }(\mathrm{h})\end{array}$ & ${ }^{\mathrm{o}}$ Brix & $\mathrm{pH}$ & $\begin{array}{c}\text { densidade } \\
\left(\mathrm{g} \mathrm{cm}^{-3}\right)\end{array}$ & $\begin{array}{c}\text { acidez total } \\
\left(\mathrm{g} \mathrm{L}^{-1}\right)\end{array}$ & $\begin{array}{c}\text { temperatura do } \\
\text { mosto }\left({ }^{0} \mathrm{C}\right)\end{array}$ \\
\hline 0 & 26,5 & 3,64 & 1,0995 & 5,960 & 27 \\
1 & 19,0 & 2,70 & 1,0750 & 7,512 & 32 \\
24 & 16,0 & 3,08 & 1,0491 & 8,760 & 29 \\
40 & 14,0 & 3,50 & 1,0306 & 7,946 & 27 \\
65 & 11,0 & 3,17 & 1,0112 & 8,008 & 27 \\
16 & 9,0 & 3,50 & 0,9957 & 8,070 & 28 \\
\hline
\end{tabular}

Tabela 4. Comparação do vinho de laranja e um vinho tinto de uva de Campo Largo-PR.

\begin{tabular}{lccccc}
\hline & turbidez (U.I.T.) & $\mathrm{pH}$ & grau Brix & grau alcólico & odor assimilado \\
\hline vinho de uva & 0,1 & 2,9 & 6,5 & 10,3 & da uva \\
vinho de laranja & 1,0 & 3,2 & 7,0 & 10,6 & da laranja \\
\hline
\end{tabular}




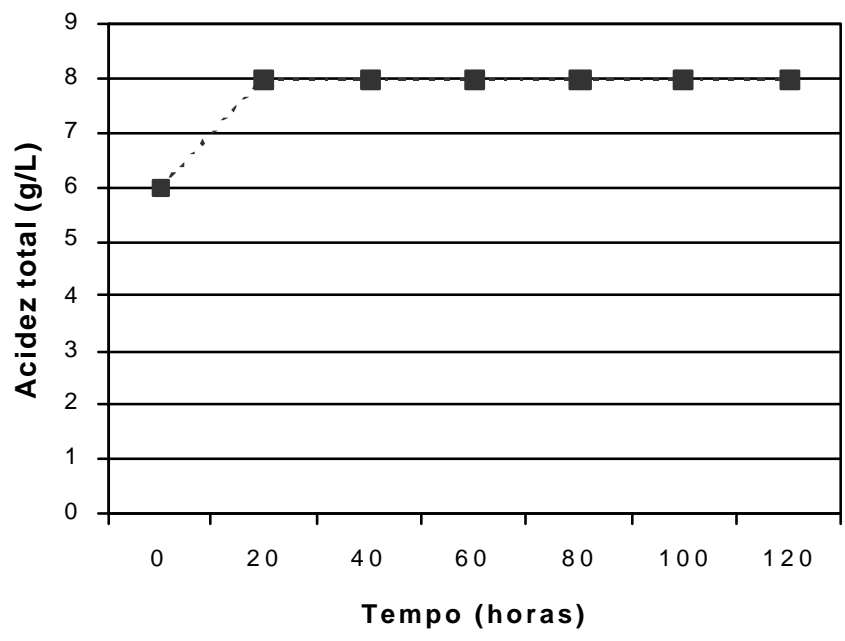

Figura 3. Variação da acidez total $x$ tempo.

vinho de laranja não houve esta preocupação, exceto pela utilização da albumina, em função das suas excelentes qualidades sensoriais.

$\mathrm{Na}$ comparação dos vinhos de laranja e uva observou-se certas semelhanças como os graus alcoólico e o Brix. Pelos espectros registrados na região ultravioleta das respectivas amostras, observou-se uma grande semelhança nas absorções em $\lambda=255$ e $264 \mathrm{~nm}$, indicando inclusive os baixos níveis de compostos fenólicos ou outras substâncias aromáticas. A produção caseira do vinho de laranja poderá ser vantajosa, devido ao baixo custo da fruta e a relativa facilidade de fermentação por leveduras selecionadas. O sabor e a qualidade sensorial do vinho é comparável com o vinho de uvas.

\section{REFERÊNCIAS}

1. Paraná citrus S/A, Boletim Técnico, 2000: http:// www.paranacitrus.com.br

2. Instituto de Economia Agrícola e Coordenadoria de Assistência Técnica Integral. Informações Econômicas, São Paulo-SP, 2000; p 99.

3. Hashizume, T.; Manual prático da fabricação de vinhos de frutas. ITAL-Instituto de Tecnologia de Alimentos, Campinas-SP, 1991; p 3.

4. Regodón, J. A.; Pérez, F.;Valdés, M. E.; Miguel, C. de; Ramírez, M.; Food Microbiol. 1997, 14, 247.

5. Cancalon, P. F.; Parish, M. E.; Food Microbiol. 1995, 12, 117.

6. Aleksander, C.; Joanna, L.; Joanna, S.; Przem. Ferment. Ow.-Warzywny 1998, 42, 17.

7. Kennes, C.; Dubourguier, H. C.; Albagnac, G.; Nyns, E. J.; J. Appl. Bacteriol. 1991, 70, 380.

8. Kennes, C.; Veiga, M. C.; Dubourguier, H. C.; Touzel, J. P.; Albagnac, G.; Naveau, H.; Nyns, E. J.; Appl. Environ.Microbiol. 1991, 57, 1046.

9. Kennes, C.; Dubourguier, H. C.; Albagnac, G.; Naveau, H.; Veiga, M.; Nyns, E. J.; Appl. Microbiol. Biotechnol. 1991, 35, 369.

10. Pérez-Coelho, M. S.; Briones Pérez, A. I.; Ubeda Iranzo, J. F.; MartinAlvarez, P. J.; Food Microbiol. 1999, 16, 563.

11. Singleton,V. L.; Trousdale, E.; Zaya, J.; Am. J. Enol. Vitic. 1979, 30, 49.

12. Pereira, I. M.; Moretti, R. H.; Ciênc. Tecnol. Alimen. 1997, 17, 192 . 